\title{
Clinical utility gene card for: Prototypic hereditary recurrent fever syndromes (monogenic autoinflammatory syndromes)
}

\author{
Martina Witsch-Baumgartner ${ }^{\star, 1}$ and Isabelle Touitou ${ }^{2,3,4}$ \\ European Journal of Human Genetics (2015) 23, doi:10.1038/ejhg.2014.257; published online 19 November 2014
}

\section{DISEASE CHARACTERISTICS}

1.1 Name of the diseases (synonyms)

Familial Mediterranean fever (FMF)
Hyper-IgD syndrome (HIDS)
Tumor necrosis factor receptor-
associated periodic syndrome
(TRAPS)
Cryopyrin-associated periodic syn-
dromes (CAPS)

Familial cold urticaria 2 (FCAS2)
Recurrent polyserositis, familial paroxysmal polyserositis, periodic disease Hyperimmunoglobulinemia and periodic fever syndrome, periodic fever, Dutch type is a mild type of mevalonate kinase deficiency (MKD)

Periodic fever, familial, autosomal dominant; familial hibernian fever; TNF receptorassociated periodic syndrome Including familial cold urticaria (FCAS), Muckle-Wells syndrome and chronic infantile neurologic cutaneous and articular syndrome (CINCA), also known as neonatal onset multisystem inflammatory disease (NOMID) NLRP12-associated periodic syndrome (NAPS12)

1.2 OMIM\# of the diseases

\#249100

\#260920

\#142680

\#607115

\#611762

Mild Autosomal recessive disease too. It is caused by mutations in the

MKD mevalonate kinase (MVK) gene. About 107 different mutations have been described and most patients have a change in both copies of their gene. Reference sequence to use is NM_000431.2 or LRG_156. Most frequent mutations that are clearly pathogenic: c.59A $>C$ (p.(His20Pro)),

1.3 Name of the analyzed genes

MEFV (NG_007871.1)

MVK (NG_007702.1)

TNFRSF1A (NG_007506.1)

NLRP3 (NG_007509.2)

c.803T >C (p.(lle268Thr)), c.815C > T (p.(Ser272Phe)), c.1129G >A (p. (Val377|le)). ${ }^{1}$

TRAPS Is an autosomal dominant disease due to mutations in tumor necrosis

NLRP12 (NG_008651.1)

factor receptor superfamily 1 A gene (TNFRSF1A). As only one abnormal copy of the gene is required to cause disease, many patients have family members who also have the disease. Reference sequence to use is NM_001065.3 or LRG_193. Most frequent mutations that are clearly

1.4 OMIM\# of the genes

*608107 pathogenic: c.175T >C (p.(Cys59Arg)), c.185G >A (p.(Cys62Tyr)), c.211_213delGAC (p.(Asp71del)), c.236C > T (p.(Thr79Met)),

\subsection{Mutational spectrum} database (http//fmf igh cnrs.fr/ISSAID/infevers/). There are mutation known with confirmed pathogenic effect, but many of the listed one mutation in one of these genes, but even in recessive disease and after extensive search no second mutation was identified. ${ }^{1}$

FMF Most common of fever syndromes. It is due to mutations in the MEFV gene. FMF is a recessive disease and about $85 \%$ of patients from the Mediterranean origin and matching established clinical criteria ${ }^{2}$ have a FMF patients only one mutation is identified. ${ }^{3}$ In about $80 \%$ of the cases mutations are detected in exon 10 of MEFV gene, some other mutations mutations are detect in 1,8 , and 9 . Reference sequence to use is NM_000243.2 or LRG_190. Most frequent mutations that are clearly pathogenic: c.2040G $>$ A or c.2014G $>$ C (p.(Met680Ile)), c.2080A $>$ G (p.(Met694Val)), c.2079G >C (p.(Met694lle)), c.2177T >C (p. (Val726Ala)), c.2230G > T (p.(Ala744Ser)), c.2282G >A (p. (Arg761His)). ${ }^{1}$

${ }^{*} 251170$

\footnotetext{
${ }^{1}$ Division Human Genetics, Medical University Innsbruck, Innsbruck, Austria; ${ }^{2} \mathrm{CHRU}$ Montpellier, Laboratoire de génétique des maladies rares et autoinflammatoires, Montpellier, France; ${ }^{3}$ Université de Montpellier, UM1, Montpellier, France; ${ }^{4}$ INSERM U844, Montpellier, France

${ }^{*}$ Correspondence: Dr M Witsch-Baumgartner, Division Human Genetics, Medical University Innsbruck, Peter-Mayr-Str.1, A 6020 Innsbruck, Austria. Tel: +43 512 900370545 ; Fax: +43 5129003 73510; E-mail: witsch-baumgartner@i-med.ac.at
}

Received 12 November 2013; revised 8 October 2014; accepted 14 October 2014; published online 19 November 2014 
c.242G $>$ A (p.(Cys81Tyr)), c.251G >A (p.(Cys84Tyr)), c.306C $>$ G (p. (Cys102Trp)) (usual names C30R, C33Y, D42del, T50M, C52Y, C55Y, C73W).

CAPS Dominant and about 75\% of patients with milder disease have affected relatives. CINCA, at the most severe end of the clinical spectrum, is often due to de novo mutations in the NLRP3 gene and there are usually no affected relatives. Reference sequence to use is NM_004895.4 NM_001243133.1 or LRG_197. Most frequent mutations that are clearly pathogenic: c.778C > T (p.(Arg260Trp)), c.907G >A (p.(Asp303Asn)), c.914T>C (p.(Leu305Pro)) c.931G >A (p.(Glu311Lys)), c.1043C > T (p.(Thr348Met)), c.1058T >C (p.(Leu353Pro)), c.1316T >C (p. (Ala439Val)).

FCAS2 Is dominant and mutations in NLRP12 gene are at the origin of this disease. Reference sequence used is NM_144687.2, but still there is no LRG. First described mutations were c.850C > T (p. (Arg284*)) and c.2072+2dupT. ${ }^{4}$ Now about 30 mutations are known (Infevers; http:// fmf.igh.cnrs.fr/ISSAID/infevers).

\subsection{Analytical methods}

The method of choice for all genes is sequencing exons and intronic boundaries. Because the most frequent clearly pathogenic mutations cluster in specific exons (MEFV: exon 10; TNFRSF1A: exons 2-3-4; and NLRP3: exon 3), it is not necessary in routine procedure to analyze all exons for each gene. See EMQN guidelines. $^{1}$

\subsection{Analytical validation}

External quality assessment (EQA) may be performed regularly, for example, in Europe by EMQN schemes.

\subsection{Estimated frequency of the diseases (Incidence at birth ('birth} prevalence') or population prevalence)

\begin{tabular}{ll}
\hline FMF & $\begin{array}{l}\text { 1/250 to } 1 / 500 \text { in Sephardic Jews and 1/1000 in the Turkish } \\
\text { population }\end{array}$ \\
Mild & Is very rare and most common in people from North Western Europe \\
MKD & \\
TRAPS & Is very rare and affects about 1 person in a million in Europe \\
CAPS & Is very rare and most patients are of European ancestry,7 \\
FCAS2 & $\begin{array}{l}\text { As rare as CAPS and less (Genetics Home Reference: http://ghr.nlm.nih. } \\
\text { gov/condition/familial-cold-autoinflammatory-syndrome) }\end{array}$
\end{tabular}

\subsection{Diagnostic setting}

\begin{tabular}{lcc}
\hline & Yes & No \\
\hline A. (Differential) diagnostics & $\bigotimes$ & $\square$ \\
B. Predictive testing & $\bigotimes$ & $\square$ \\
C. Risk assessment in relatives & $\bigotimes$ & $\square$ \\
D. Prenatal & $\square$ & $\square$ \\
\hline
\end{tabular}

\section{Comment:}

Depending on countries and age of individuals predictive testing and risk assessment is allowed and performed or not. Prenatal diagnosis may be discussed in some cases of CINCA (CAPS).

\section{TEST CHARACTERISTICS}

\begin{tabular}{ccccc}
\hline & \multicolumn{2}{c}{ Genotype or disease } & A: true positives & C: false negatives \\
\cline { 2 - 3 } & Present & Absent & B: true positives & C: true negatives \\
\hline $\begin{array}{c}\text { Test } \\
\text { Pos. }\end{array}$ & A & B & Sensitivity: & A/(A+C) \\
Neg. & C & Specificity: & $\mathrm{D} /(\mathrm{D}+\mathrm{B})$ \\
& & & Pos. predict. value: & $\mathrm{A} /(\mathrm{A}+\mathrm{B})$ \\
& & & Neg. predict. value: & $\mathrm{D} /(\mathrm{C}+\mathrm{D})$ \\
\hline
\end{tabular}

\subsection{Analytical sensitivity}

(proportion of positive tests if the genotype is present)

Depending on the quality of sequencing almost $100 \%$ for $M E F V-$, MVK - , TNFRSF1A - , NLRP3 - , and NLRP12 - genes

\subsection{Analytical specificity}

(proportion of negative tests if the genotype is not present)

Depending on quality of sequencing almost $100 \%$ for $M E F V-$, MVK - , TNFRSF1A - , NLRP3 - , and NLRP12 - genes

\subsection{Clinical sensitivity}

(proportion of positive tests if the disease is present)

The clinical sensitivity can be dependent on variable factors such as age or family history. In such cases a general statement should be given, even if quantification can only be made case by case.

There are many causes for recurrent fever attacks; hence, it is difficult to define a clinical sensitivity. In cases where two mutations are identified, for example, the $M E F V$ gene, it is presumed, because of high analytical sensitivity, that the patient has FMF.

\subsection{Clinical specificity}

(proportion of negative tests if the disease is not present)

The clinical specificity can be dependent on variable factors such as age or family history. In such cases a general statement should be given, even if quantification can only be made case by case.

There are many causes for recurrent fever attacks; hence, it is difficult to define a clinical specificity. In cases where no mutation is identified, for example, in the $M E F V$ gene, it is presumed, because of high analytical specificity, that the patient has not FMF due to mutations in the MEFV gene, but it does not exclude a clinical diagnosis of FMF, and hence a corresponding treatment has not to be excluded.

\subsection{Positive clinical predictive value}

(life time risk to develop the disease if the test is positive) All these monogenic autoinflammatory syndromes (FMF, MKD, TRAPS, CAPS, and FCAS2) are children's diseases, hence adult onset is unusual. However, the FMF patients carrying the homozygous p.Met694Val genotype have obviously higher life time risk to develop amyloidosis. ${ }^{8}$

\subsection{Negative clinical predictive value}

(probability not to develop the disease if the test is negative) Assume an increased risk based on family history for a non-affected person. Allelic and locus heterogeneity may need to be considered.

There are many causes for recurrent fever attacks; hence it is difficult to define a negative clinical predictive value. For example, in cases where no mutation is identified in the $M E F V$ gene, it is presumed, because of high analytical specificity, that the patient does not have FMF at least due to mutations in the $M E F V$ gene, but it does not exclude a clinical diagnosis of FMF from criteria described by Livneh et al. ${ }^{2}$ 


\section{CLINICAL UTILITY}

3.1 (Differential) diagnostics: the tested person is clinically affected (To be answered if in $1.9^{\text {' }} \mathrm{A}$ ' was marked)

3.1.1 Can a diagnosis be made other than through a genetic test?

FMF HIDS (Mild TRAPS CAPS FCAS2

$M K D)$

No (continue with 3.1.4)

Clinically

$X$

$\mathrm{X}$

$x$

$x$

\section{$x$}

$x$

$x \quad x$

Imaging

Endoscopy

Biochemistry

Electrophysiology

Other (please describe)

If therapy with $2 \times$ serum

positive. $\quad>100 \mathrm{E} / \mathrm{ml}$

In Livneh (but not

et $a P^{R}$ there specific)

are described

diagnostic cri-

teria for FMF. colchicines is $\operatorname{lgD}$

3.2 Predictive setting: the tested person is clinically unaffected but carries an increased risk based on family history

(To be answered if in 1.9 'B' was marked)

It is better not to test unaffected individuals. In cases with risk of amyloidosis it may be useful to know the genotype.

3.2.1 Will the result of a genetic test influence lifestyle and prevention?

If the test result is positive (please describe)

If necessary symptoms have to be treated and kidneys have to be observed.

If the test result is negative (please describe)

Genetic testing was done because of symptoms hence despite negative test result the patient will be treated as necessary.

3.2.2 Which options in view of lifestyle and prevention does a person at-risk have if no genetic test has been done (please describe)?

Not applicable because the patient has symptoms and in any case that will be treated as possible.

3.3 Genetic risk assessment in family members of a diseased person (To be answered if in 1.9 'C' was marked)

3.3.1 Does the result of a genetic test resolve the genetic situation in that family?

It may sometimes resolve the genetic situation in a family.

3.3.2 Can a genetic test in the index patient save genetic or other tests in family members?

Yes, genetic testing saves genetic or other testing in family members.

3.1.2 Describe the burden of alternative diagnostic methods to the patient

Delay in diagnostic resulting in life threatening complications (all diseases);

Multiple surgery unnecessary explorations (especially in FMF and maybe in TRAPS)

3.1.3 How is the cost effectiveness of alternative diagnostic methods to be judged?

Not applicable

3.1.4 Will disease management be influenced by the result of a genetic test?

\begin{tabular}{|c|c|c|c|c|c|}
\hline & $F M F$ & Mild MKD & TRAPS & CAPS & FCAS2 \\
\hline No & $\begin{array}{c}\text { In any case } \\
\text { treatment } \\
\text { with } \\
\text { colchicine }\end{array}$ & & & & \\
\hline Yes & & $x$ & $x$ & $\mathrm{X}$ & $x$ \\
\hline Therapy & & $\begin{array}{l}\text { Glucocorto- } \\
\text { costeroids, } \\
\text { TNF receptor } \\
\text { IgGFc fusion- } \\
\text { protein } \\
\text { IL-1beta- } \\
\text { antagonistic } \\
\text { therapies } \\
\text { (Anakinra) }\end{array}$ & $\begin{array}{c}\text { Glucocorto- } \\
\text { costeroids, } \\
\text { TNF antago- } \\
\text { nist (Etaner- } \\
\text { cept), } \\
\text { IL-1beta- } \\
\text { antagonistic } \\
\text { therapies } \\
\text { (Anakinra) }\end{array}$ & $\begin{array}{c}\text { IL-1beta- } \\
\text { antagonistic } \\
\text { therapies } \\
\text { (Anakinra) }\end{array}$ & $\begin{array}{c}\text { IL-1beta- } \\
\text { antagonistic } \\
\text { therapy (Ana- } \\
\text { kinra) is } \\
\text { discussed }^{9}\end{array}$ \\
\hline \multicolumn{6}{|l|}{ Prognosis } \\
\hline Management & & & & & \\
\hline
\end{tabular}

3.3.3 Does a positive genetic test result in the index patient enable a predictive test in a family member?

Yes, it may partly enable predictive testing in family members.

3.4 Prenatal diagnosis

(To be answered if in 1.9 ' $\mathrm{D}$ ' was marked)

3.4.1 Does a positive genetic test result in the index patient enable a prenatal diagnosis?

Yes, by knowing the mutations prenatal diagnosis will be possible, but only in some cases of CINCA (CAPS) prenatal diagnosis may be discussed.

\section{IF APPLICABLE, FURTHER CONSEQUENCES OF TESTING}

Please assume that the result of a genetic test has no immediate medical consequences. Is there any evidence that a genetic test is nevertheless useful for the patient or his/her relatives? (Please describe)

\section{CONFLICT OF INTEREST}

The authors declare no conflict of interest.

\section{ACKNOWLEDGEMENTS}

This work was supported by EuroGentest2 (Unit 2: 'Genetic testing as part of health care'), a Coordination Action under FP7 (Grant Agreement Number 261469), and the European Society of Human Genetics.

1 Shinar Y, Obici L, Aksentijevich I et al: Guidelines for the genetic diagnosis of hereditary recurrent fevers. Ann Rheum Dis 2012; 71: 1599-1605.

2 Livneh A, Langevitz $P$, Zemer $D$ et al: Criteria for the diagnosis of familial Mediterranean fever. Arthritis Rheum 1997; 40: 1879-1885. 
3 Kotter I, Schedel J, Kummerle-Deschner JB: [Periodic fever syndrome/autoinflammatory syndrome]. Z Rheumatol 2009; 68: 137-148, quiz 149.

4 Jeru I, Duquesnoy P, Fernandes-Alnemri T et al: Mutations in NALP12 cause hereditary periodic fever syndromes. Proc Natl Acad Sci USA 2008; 105: 1614-1619.

5 Solak M, Yildiz H, Koken R et al: Analysis of familial Mediterranean fever gene mutation in 202 patients with familial Mediterranean fever. Genet Test 2008; 12: 341-344.

6 Lainka E, Neudorf U, Lohse P et al: Analysis of cryopyrin-associated periodic syndromes (CAPS) in German children: epidemiological, clinical and genetic characteristics. Klin Padiatr 2010; 222: 356-361.
7 Cuisset L, Jeru I, Dumont B et al: Mutations in the autoinflammatory cryopyrinassociated periodic syndrome gene: epidemiological study and lessons from eight years of genetic analysis in France. Ann Rheum Dis 2011; 70: 495-499.

8 Dusunsel R, Dursun I, Gunduz Z, Poyrazoglu MH, Gurgoze MK, Dundar M: Genotypephenotype correlation in children with familial Mediterranean fever in a Turkish population. Pediatr Int 2008; 50: 208-212.

9 Jeru I, Hentgen V, Normand S et al: Role of interleukin-1beta in NLRP12-associated autoinflammatory disorders and resistance to anti-interleukin-1 therapy. Arthritis Rheum 2011; 63: 2142-2148. 